DOI: 10.2478/auseb-2014-0004

\title{
Evaluation and Measurement in Local Public administration
}

\author{
Marianna Dobó \\ Eszterházy Károly College, \\ Department of Political Sciences \\ email: domar@ektf.hu
}

\begin{abstract}
The judgement of self-governmental operation and the evaluation of providing public services have been focused on since the democratic transformation. By the 1st of January 2012 (CXCIX/2011. and CLXXXIX/2011. law) amendment of the Hungarian on civil servants, the civil servants work performance evaluation system has been introduced with the consideration of the principles of the civil servants carrier programme. The purposes of this evaluation system are made in order to grow the workers management efficiency in the field of public service, and also to improve their work standards.
\end{abstract}

\section{Introduction}

In Hungary, modern bureaucracy began to develop on central and local levels in the democratic transformation period. The establishment of local governments, which has been declared by different laws for twenty years by the Legislative, was connected to state development. This division of tasks and labour meant the fundamental of local administration and contributed to the new type of local society organization. In addition, it is very important to mention that the tightening scope of public services, which are provided directly by the state, had a favourable impact on the development of local governments. As a result of this more and more occurred tasks; these were transferred to the local governance during the emerging division of labour. At the same time

JEL Classification: Z18

Key words and phrases: modern bureaucracy, local public administration, measurement, evaluation 
local governments keep referring to their tightened financial scope for action that is a barrier to governance.

"Local governmentscan becharacterized by considerable traditions in Hungary - although noble counties as the traditional elements of public administration had a much narrower scope for action". (Bőhm 1998). Local selfgovernment enables that constituent local communities can manage their local matters independently and democratically through local governments. Selfgovernment, which is thought as the synonym of autonomy, played a key-role in the development of a democratic political system. The main characteristic principle of local governments, subsidiarity - local tasks have to be handled at local level - is not yet enough. (Kákai 2008) This is alsoproved by the fact that people ascitizens get into contact especially with local governments from the governmental levels and there is an opportunity for direct representation of interests and citizen participation.

The success of self-governmental system can be ensured by its stability demands and ability to change. This can be established by the right management of decision-making process. The judgement of self-governmental operation and the evaluation of providing public services have been focused on since the democratic transformation. By the 1st January 2012 (CXCIX/2011. and CLXXXIX/2011. law) amendment of the Hungarian on civil servants, the civil servants work performance evaluation system has been introduced with the consideration of the principles of the civil servants carrier programme. The purposes of this evaluation system are made in order to grow the workers management efficiency in the field of public service, and also to improve their work standards.

Range of Subjects:

a.) Evaluation aspects: who evaluates whom, what, when and why? How far is evaluation widespread in practice? Has it got separable models?

b.) What is the motivation in the establishment of a performance increasing method - does this method focus on pre-decision and/or execution? To what extent can its effects be measured?

c.) Can this method be adapted to increase the representatives' efficiency and their formation?

The study consists of two parts. Initially, I examine the legal background, which basically determines the regulations. Everyone gave the same complex answers to the important questions; who, when why. The difference is due 
to the fact that shows the filled requirements with different content, as the leaders of the settlements implemented them. In the second parts I analyse the changes in Hungary, the latest, the 2011 Act, the creation and of districts and the consequences of it.

The altering construction, result of the changing laws modifies the work and the evaluation methods of office systems. The characteristic feature of the administrative reform is to develop a complete system comprehension. They want to change in order to create a modern public administration, which is able to respond to changes, and serve the society effectively. The preparation of these administrative reforms has its laws, however, the materialization come about in practice, at the level of individual municipalities.

My study differs from previous studies. This one gives the decision theory aspect of the administrative reforms by case studies. For the analysis I have studied the decision-making process of local government of Heves. I have also observed the division of labour among public officials and politicians as well as the strategic process.

In this thesis, I introduce the methods of performance measurement and evaluation and their impacts at local governments in Hungary - explicitly in Heves County, North-Hungary - relying on document analysis and interviews. Preparing this study, I examined the organizational and operational regulations, as well as the regulations and decisions that deal with the principles of assessment. I also attended the board meetings where the public officials gave summary account.

These observations and the available papers will help me to write further case studies (transformation of public administration, strategic planning processes, etc.), and also a policy and comparative analysis (education policy, youth policy, economic policy, local local governments and the role these public officials, etc.).

Making workers at the organizations comes up to expectations what can be achieved by different methods. Regulation tasks ensure the actual and expected behaviour that meet each other as best as possible. The regulation has to serve two things: the norms (standards have to be given and requirements must be defined); motivation and pressure must be raised so that workers will follow the example. The performance measurement, and evaluation in the case of local governments create motivational situations but it can be also demoralizing at the same time. 


\section{Laws concerning performance measurement and goals of the evaluation}

The exercise of local governments - public services have got concrete products in their internal and external services - can be measured. The local government performance and decision-making can be defined after the operationalization of concepts. The performance is determined by three points of view: economy, effectiveness and efficiency. Tamás M. Horváth has distinguished four content elements of performance dimension: economy, effectiveness, efficiency and quality.(M. Horváth 2005) He emphasizes to make the difference between concepts because the exercise of local governments can only be interpreted correctly in this way. Steve Rogers wrote about performance management of local governments and separated two applied models. (Rogers 1990) One common point of them is that performance is not connected to only one exercise but it is always a common characteristic of more different type of exercises or functions. Thus, it can be rather regarded as an organisational performance measurement.

Performance indicators and standards are distinguished in the models. The performance indicators are regarded as pre-determined characteristics according to which performance is measured - in one of the models they are presented, while in the other model they do not appear. The performance standards are the measures that if they are achieved, we can ascertain of goal access. In the simple model efficiency lies in the centre and it focuses on citizens. Needs can be regarded as opportunities because they are the factors which form the market. At the evaluation of the effects the subjects of investigation can be the changing needs, the results of activities or citizens opinions. In the complex model decision-making is weaved through complementary services which favourable or negative effects - if there is no complementary service - causes the appearance of a need for resources. These two models above provide performance measurement opportunities in practice while general normative model can be used in theory. In the latter case measures, criteria and output indicators are linear and well-separable. Steve Rogers considers this model, which characterization of measures and effects one by one becomes both exclusive and important in the control, as well as in the in-theory evaluation (Rogers 1990). He uses different market tests, which human resources are also investigated with, for economy measurement. In the study of effectiveness average unit costs and productivity rates are applied. This type of effectiveness analysis that connects the input and output sides, provides comparative analysis 
at two alternative indicators. Goal achievements in efficiency are examined through public opinion researches.

The role of performance evaluation does not have to be over-dimensioned but the lack of performance evaluation leads to such situations where control is completely eliminated from decision-making and implementation process. In addition, decisions have to be made when potential effects cannot be predicted and tasks cannot be solved.

The steps and methods of measurement are not easy to set up. In the United States of America, organizations make performance evaluation and flow charts; such methods as connect to them the local governments. (Based on the authors data gathering, performance measurement in Burlington - NC, USA, 2004). In parallel with the decision making process, the important fields of effects with criteria of success begin to be determined, then the selection of performance indicators based on experts opinions starts. Identification of the current situation and attainable serve purpose change help the designation of objectives. After data consideration, information appears in the labour process that is examined and the evaluation of the effects comes at last. In the evaluation, attention is called to the fact and suggestions cannot be made only with the help of objective indicators, but evaluation of subjective elements are also important, thus outsider and top-controlled characteristics of the decision-making can be prevented and decisions can be transmitted to the local society more easily.

Measurement is an integral component of any drive to improve productivity. Measurement of service performance is notoriously difficult but possible. Local authorities form a significant part of the service sector. Performance measurement in a local authority is a complex task because local authorities offer a wide range of services with both tangible and intangible outputs; customers rarely pay an economical price for the services; there is no profit measure and there is no apparent direct link between services and the cost to the electorate (Gobbadyan and Ashorth 1999).

The controlling character sums up comprehensively if the local government works effectively and efficiently. It is not a task composed of one action but it means a compound, complex task. After the acceptance of the decision proposal, the evaluation covers the examination of the whole process and its effects. The ideal period for this kind of decision revision is budgeting. The purpose of performance control is offering different public services is the investigation of the realization of the three Es - economy, effectiveness and efficiency - , the assurance of economical public funds use and the assertion of "value for money" principle (Palmer 1993). 
"The Economy - the terms and conditions under which an organization acquires human and material resources, an economic organization acquires these resources in appropriate quantity and quality and at least cost. The Efficiency - the relationship between the goods and services produced and the resources used to produce them, an efficient organization produces the maximum output for any given set of resource inputs, or minimizes the inputs necessary to produce given the quality and quantity of outputs. The Effectiveness - the extent to which the defined task or work programme has been accomplished in relation to overall aims." (Palmer 1993)

Regulation that is often identified with the so-called regulatory system is an inherent part of the management system. The regulation influences the whole management, thus it is not a single mechanism but it appears in different fields of cooperation. The regulation has got several principles; one of the most important principles is the (external and internal) system of written legal norms.

The basic dilemma of regulation is the ratio and the role of manipulation also what the constraining should be; because the nature of legal norms is enforcement. In addition, it is not insignificant what should be regulated. Different goals can be achieved if the regulation is substantially or detailed, it investigated in the past, the present or the future, it concentrates on the process or the results, and it handles every occurrence equally or examines only exceptional cases. The essence of effective regulation is that the demanded effect is obtained with the smallest intervention and restriction while auto-guided processes are given ground.

Johnsen has proposed a set of ideal indicators, which need to satisfy the following criteria: consistency, comparability, clarity, controllability, contingency, relevance and feasibility. He takes the criteria of relevance as the most important. Many applications require specific relevant to special needs conditions (Johnsen 2005).

In Hungary several laws and government decrees have been passed since the democratic transformation, in order to performance evaluation in the public sphere could adopt the European norms. The law on civil servants (Law no. 23/1992 and 36/2001) have been published in 1992, in 2001 and in 2011 a law was passed on workers legal relations in the public administration (Law 72/2006). In 2006 the amendment about performance evaluation has affected many areas: decisions on salary payments must be made with the evaluation of civil servants professional work; it reversed the regulation that says the rules of performance measurement do not have to be used if the civil servants job turnaround does not exceed six months in the actual year. Out of turn 
qualification is prescribed if it is presumable that the civil servant does not fulfil or just fulfil to a small degree at low level (Law 72/2006, Act 34, Section B ). With another legislation (Law 121/2006, Law CLXXXIX/2011) in 2006 performance measurement rules have been extended over executive officers and counsellors. This law established the legal basis of the new performance measurement system. The law was wanted to be strengthened by a government decree (Government decree 301/2006 (XII. 23.) which is also about the rules of rewarding.

It is always difficult to fulfil the legislative change. The new and the old rules insertion cause interpretation problems, not the following of the changes. This is particularly true if the earlier system of rules will be replaced by a new law, which in practice is not evolved yet.

The Government Personnel Strategy was created, which affects the careers goals and directions.

The civil service still needs the specialty of the public policy; administration and public management, - these are the starting points of the agenda.

The purposes of the implementation of performance evaluation are that requirements need to be determined and executives are constrained to revise job descriptions and other organizational documents regularly. The performance evaluation helps to motivate civil servants and rewards individual efforts as well as the professional work in order to develop the workers abilities in the interests of organizational achievements.

The performance evaluation owns a compulsory evaluation aspects, and principles that are written in the Law on civil servants means the qualification of the civil servants right and the employers commitment. The evaluation of professional performance and the measurement of performance influential knowledge, and also the abilities, and characteristics as well as the professional progress are made in the first place. The civil servants performance evaluation must be done within every four years, it is also compulsory when they are ranked above. The legal consequence is the acceleration or retardation of their progress.

The performance evaluation can be divided into phases: as the first step the qualification system is prepared, an aspect system is set and outlined to the civil servants. The document has to be given to the valuated person after the evaluation, who can complain the text and the preparation circumstances then. Besides interest representation, the organizations have commenting rights or the evaluation can be contested in court, because of incorrect or untrue statements that violate private rights.

To completely revise and change local and internal rule systems of each local 
government - which would mean their total rethinking in practice - is unnecessary and almost impossible. The important approach occurs maybe if the most necessary changes are implemented. The need for rule changing has to be sought along new elements in the whole rule system. The implementation and systemic character of the conceptionally rethought regulation means primary importance during the formation of performance evaluation.

Activity regulation and organization of local governments meant the prescription of internal and external legal norms (rights, commitments, responsibilities and sanctions) which institutionalize the operational system, and accidentally make it enforceable. Major purposes are laid in this system. The body of representatives decides on them and they are always connected to the operation and economy of the local government or administrative cases. The purposes are usually decided upon the following fields; the programme of local government session, the annual program of the body of representatives, the rules of organization and operation, the settlement development conception, the development strategy of public services, and also the task plans that connected to it. Besides it can be influenced by the examination of local cooperation opportunities or determinations of the National Audit Office.

Law number CLXXXIX/2011 includes the civil servant's works capacity is rated in a writing assessment by the employer. Performance evaluations have compulsory and recommended parts.

At least four performance evaluations compose the qualification result of the civil servants. It is necessary to consider in each year. The Ministry of Public Administration and Justice release a methodological recommendation to support the evaluations process.

Taking into consideration the sentences above, since March 1, 2012, the employer has been continues to make the performance evaluation of a predefined performance requirement.

The focus of evaluation method can be summed up in five questions: who, whom, when, why and how evaluate?

WHO? - The evaluator is in most cases the direct superior of the evaluated person or he is the subordinate or the more superior worker in some cases. If it is exist, the evaluator is the human resource organization. In Hungary the evaluation right is in the employers authority, it is also relevant to local governments.

WHOM? - Every civil servants are evaluated by determining rotation and in appointed time. The evaluation of certain groups or occasional communities can affect the work positively. In more local governments, that type of evaluation promotes performance better than the individual evaluation, because of 
the stimulating effect of workers comparison that may motivate the individuals performance. The only occurring venture - which must be avoidable - are the emerging conflicts and their resolution.

WHAT? - The most accurate information about the evaluation aspect system is the most visible requirement before the evaluation. The evaluation gets several substances in its centre such as the individual opinion about the objective; the public servants level of cooperation and knowledge; his or her responsibility besides the conflict management skills, as well as the professional experience and motivation. It is also essential that possible future opportunities and developments relates to these conclusions.

WHEN? - Examinations in every four years are too rare to be effective. It can be the base of personal decisions related to the case of more negative results condemnation and/or exemption may come. This question is the significance of evaluation in many times.

HOW? - Two types of methods are used; on the one hand, the affected people are evaluated separately, in the other hand, groups are usually evaluated (according to its advantage, the better and the worse performers can be identified in the group, too). The evaluation is based on actual data (these may be more objective) and opinions (subjective factor). In 2001 György Hajnal established two methodological approaches; measuring - evaluating and developing and, in addition the supporting. The data of evaluations are given in terms of numbers and the reward or punishment are issued by their values. Sometimes the objective data show less information, what can cause serious stress both the executive and the evaluated persons, therefore this means the disadvantages of that method. It can lead to alienation or causes lack of motivation. In the developing - supporting method, the stress defines the communication between the evaluator and the evaluated persons. Discussion of problems and the methods can help enhance the work performance. There are several disadvantages such as the lack of objective data that can show the necessary staff decisions. The mixture of the two methods exists in practice. However, they cannot be mixed with each other to any length because Hajnal showed the case of huge consequences honesty in communication falls. 


\section{The experiences of the performance measurement system at local governments in Heves county (case study)}

The group evaluation was rarely applied at the local governments; instead of this method, individuals were evaluated one by one strictly according to the specific legal framework. Evaluators aspired to objectivity; however, sometimes it was ostensible. Most of the civil servants performed well or excellently and nobody failed the exam in that period which was found unfair by a lot of affected workers. The performance evaluation happens in the following way at examined local governments:

- At the local governments, thebody of representatives decides on priority goals which will be the base of performance requirements (Law on civil servants, Article 34, Section 3)

- According to the goals that are appointed by the local government and the civil servant's job descriptions the public notary on his/her employers authority - as the Hungarian practice, the public notarys employer the mayor itself - determines the performance requirements needed for the evaluation of civil servant's work performance in a written document every year in forward. (Law on civil servants, Article 34 (1), (4), (5), $(6))$

- With the consideration of the primary goals and job descriptions, the employer evaluates the civil servant's work performance in a written annually by acting in his/her discretionary jurisdiction. The notary's performanceis evaluated by the mayor whoinforms the body of representatives of the evaluation. (Law on civil servants, Article 34 (1), (4) and $(6))$

- The goal of performance evaluation is to raise the level of civil servants' professional work; civil servants work in accordance with the intentions of the local government and in conformity with the actual administrative requirements.

- On the one hand the performance evaluation establishes possibilities for a higher financial recognitionto civil servants; on the other hand it gives an opportunity to lower under-performing civil servants' salary. 
The Mayor's Offices have to dothe following tasks to manage their exercises that are connected to the exercises of public functions, pre-decision and implementation of a higher standard:

1. To modernize public services continuously and provide local quality public services.

2. To strengthen service characteristic in the administration and effectiveness of citizen friendly administration means and methods (the application of the new law on the rules of public administration and public proceedings, the lowering of administration time-limits, giving complete information to clients and raising of legal standards of administration).

3. To establish an IT base of the public administration in order to implement document management according to legislative prescriptions and make administration procedures appropriate for e-Administration.

4. To arrange parliamentary and local elections legally and professionally in 2010 .

5. To collect taxes especially communal ones and ensure a smooth switch of trade tax transfer to Hungarian Tax and Financial Control Administration.

The local governments determined goals in order to implement these tasks:

- The practice of local government rights has to be supported with wellestablished local authority pre-decisions and also must ensure permanent control of implementation especially at decisions about settlement development, public service management and the raising of quality level;

- To manage the local government funds; ensure the protection and renewing of the institutional buildings in regard to the establishment of the settlement - image;

- During the implementation of the local government budget in 2010 the conformity of rules has to be ensured in financial management; purposive, effective and economic aspects connected to financial management that must have been emphasized. Rational financial management is also needed.

- Financial and accounting discipline has to be strengthened and continuous executive control has to be provided. 
- The effectiveness of internal control needs further development.

- General legal practice must be established with the implementation of the law and amendments to the general rules of administrative procedures and services 140/2004. E-administration and electronic document management must be extended in stages.

- Better recognition of enactments has to be promoted and codifications of local legislation areas have to be provided.

- The local governments have to pay great attention to the organization and arrangement of parliamentary and local elections.

- There is need an adequate client information, besides make the IT backgrounds more suitable for e-Administration and the development of settlement websites must be continuous.

- The establishment and implementation with the corrections of official control methods have to be better harmonized by control systems; serious sanctions and legal consequences are defined by the local governments that have to make a firm stand against unlawful citizens and organizations.

- The opportunities for national and EU proposals and funds need to be continuously watched.

- If it is necessary, the local governments have to conduct reconciliation of interests, social consultation or population forums.

- Increased attention is needed to the modernization of official registration, document management system and archival work.

The performance evaluation in determining the underlying goals are usually taken into account in addition to the city's medium-term development plan, concept development, and citizen-friendly, service and legal expectations against the office operation.

Although the existing legislation -regarding to the accomplishment demand -does not contain a clause according to which the basic aims of the accomplishment demand must be decided by the Representative Body

Having regard to the fact that the Mayor's Office annual performance requirements of 2013 include the municipal functions, it was important for the leaders of the settlements that the Board of Representatives approve the aims. 
At the examined local governments the performance evaluation occurs according to a closed qualification system: aspects and dimensions are predetermined and the evaluation has to be done quantified. There are several disadvantages of this practice: it is inflexible and it cannot be adapted to certain job descriptions. An advantage of the system is the comparable work performance (so that staff decisions can be taken more easily), however, its negative side is more prominent because the results are not collected or systematized, and thus the qualification is rather symbolic. There is no unambiguous output, the measurement system, the indicators and the expected performance are often unreal and in many cases performance measurement is not followed by salary discounts. In addition, adjustment is difficult to short-term goals and more difficult to medium-term period programmes, especially because they are more unclear.

The criticism of the system appears related to the rarely happens qualifications, and performance evaluation takes place annually, therefore changes in inappropriate behaviour and motivation are uneasy. The communication of executives judgement to employees, career decisions, management of documents about discipline or removal, forwarding of organisational decisions to personal level are all difficult. There is no progress and the implementation of performance measurement system causes stress and conflicts.

\section{Summary}

The study demonstrates that the performance management is a process that controlled by the organization's leaders, and determines the individual actors duties in order to achieve the strategic purposes. For this reason, they try to augment the systemic and the individual performance, alike the performance evaluation system with the motivational system, they also expand the competence development and quality assurance, as well as the remuneration decisions.

The individual departments and the employees need to know how to contribute to the organizational goals in order to fulfil the organization's strategic goals. The individual goals, however, are not constant, they are revised regularly. The performance management allows the leader and the employee to re-think the job description, and modify it together if it is necessary.

The measurement and the evaluation are becoming increasingly important in the public administration system. On 1 January, 2013, the evaluation system was transformed. Zoltan Magyaris administration-development program serves 
the development of Hungarian public administration for the renewal of public administration as well as its staff, implementing a high level of professional knowledge and the development of new staff career modes which are defined as priority areas.

Further questions that can be investigated: what forced paths appear in the exercise of local governments, how these paths can be prevented? What mean the consequences of the deficit of the Hungarian management reforms through the eyes of EU member states? Can performance evaluation and increase can be adapted to the local government representatives?

\section{References}

Bőhm, Antal (1988), Successful settlements. Budapest: Agroinfo

Eliassen, Kjell and Kooiman, Jan (1997): Managing Public Organizations. SAGE Publications, London.

Ghobadian, Abby and Ashworth, John (1994) Performance Measurement in Local Government - Concept and Practice, International Journal of Operations 83 Production Management, Vol. 14 Iss: 5, pp.35 - 51.

Hajnal, György (2008): Advancing available knowledge on Hungarian policy failures, Budapest: KSZK

Johnsen, Åge (2005), What Does 25 Years of Experience Tell Us About the State of Performance Measurement in Public Policy and Management? Public Money 83 Management Vol. 25, Iss. 1,

Kákai, László (2008): Self-government for you, but without you. Budapest: Századvég

Lőrincz, Lajos (1996): Anthology of Administrative Sciences. Budapest: Eotvos University

M. Horváth, Tamás (2005): Public management. Pécs - Budapest: Dialog Campus

Palmer, Anna J. (1993), Performance measurement in local government, Public Money and Management, 3 (October-December) pp. 31-36

Rogers, Steve (1990): Performance Management in Local Goverment. LONGMAN: LGTB

Verebélyi, Imre (1996): Public Administration Reform Program. Goverment Commissionr for Modernisation of Public Administration. Budapest,

Wilson, Wodrow (1987): The Study of Administration. Political Science Quartly 1987. 
Zupkó, Gábor (2002): Trends in administrative reform at the millennium, Budapest: Századvég

\section{Legislative acts:}

Law no. 23/1992 and 36/2001

Law $72 / 2006$

Law 72/2006, Act 34, Section B

Law $121 / 2006$

Law CXCIX/2011.

Law CLXXXIX/2011.

Government degree 301/2006 (XII. 23.)

evaluation, measurement in Heves County 